\title{
Effect of glutamine supplementation on left colon healing in rats with extrahepatic biliary obstruction ${ }^{1}$
}

\author{
Hugo Muscelli Alecrim', Sérgio Andurte Carvalho Duarte ${ }^{\mathrm{I}}$, Maria Eduarda Bonavides Amaral ${ }^{\mathrm{II}}$, Filipe Diógenis ${ }^{\mathrm{II}}$, Fabiana \\ Pirani Carneiro'III, João Batista de Sousa ${ }^{\text {IV }}$
}

DOI: http://dx.doi.org/10.1590/S0102-86502015001000010

I'Graduate student, School of Medicine, Brasilia University (UnB), Brazil. Grant from Institutional Program for Scientific Initiation (PIBIC), of the National Council of Scientific and Technological Development (CNPq), Ministry of Science, Technology and Inovation, Brazil. Acquisition and interpretation of data, manuscript preparation, statistical analysis.

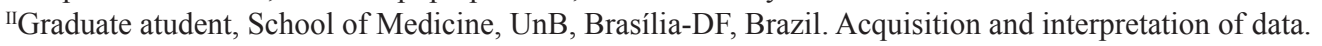

IIIPhD, Associate Professor, Division of Pathology, School of Medicine, UnB, Brasília-DF, Brazil. Macroscopic and histopathological examinations. interpretation of data, statistical analysis, critical revision.

${ }^{\text {IV }} \mathrm{PhD}$, Associate Professor, Division of Surgery, School of Medicine, UnB, Brasília-DF, Brazil. Intellectual and scientific content of the study, designed the protocol, provided guidelines for the surgical interventions, supervised all phases of the study, manuscript writing, critical revision.

\begin{abstract}
PURPOSE: To evaluate the influence of glutamine and obstructive jaundice on left colon healing in rats.

METHODS: Sixteen male rats were allocated across four groups: LG - Common bile duct ligation followed by colotomy and bowel suture on postoperative day 7 . Supplementation with glutamine $2 \%$ from day 4 after duct ligation until euthanasia. L - Common bile duct ligation followed by colotomy and bowel suture on postoperative day 7 . No glutamine supplementation. M - Common bile duct manipulation followed by colotomy and bowel suture on postoperative day 7. No glutamine supplementation. MG - Common bile duct manipulation followed by colotomy and bowel suture on postoperative day 7 . Supplementation with glutamine $2 \%$ from day 4 after duct manipulation until euthanasia. On the day of euthanasia, bursting pressure of the sutured bowel segment was measured and samples were collected for histopathological analysis.

RESULTS: There were no differences in bursting pressure among groups : LG vs. M (110 \pm 28 vs. 173 $\pm 12 ; \mathrm{p}=0.08)$. Groups $\mathrm{L}$ and MG were not different from group M (156 \pm 12 and $118 \pm 22$. Glutamine supplementation was associated with less edema, polymorphonuclear lymphocyte infiltration, bacterial colonies, and abscess formation, as well as with increased collagen formation.
\end{abstract}

CONCLUSION: Obstructive jaundice had no negative effect and glutamine supplementation had no positive effect on colonic scar strength in rats.

Key words: Glutamine. Jaundice. Colon. Wound Healing. Bilirubin. Colorectal Surgery. Rats. 


\section{Introduction}

Several studies have suggested that obstructive jaundice is associated with increased incidence of surgical complications, such as anastomotic dehiscence, incisional hernia, and surgical site infection ${ }^{1-3}$. Hyperbilirubinemia could have negative effects on healing as it impairs the proliferation of fibroblasts and immune cells $^{3}$. Furthermore, cholestasis is associated with changes in liver function, which can affect the processes involved in healing ${ }^{4}$.

Glutamine is a five-carbon non-essential amino acid ${ }^{2,5}$. It is the most abundant amino acid in plasma, cerebrospinal fluid, and skeletal muscle. The majority of cells and tissues are able to synthesize glutamine from glutamate and ammonia, in a process catalyzed by the enzyme glutamine synthetase (GS). Glutamine is a key component of nitrogen metabolism and behaves as an important transporter and store of glutamate and ammonia ${ }^{6}$. This amino acid can originate several other substances, including some of particular importance to regenerative processes, such as glutathione, proline, purines, and pyrimidines ${ }^{2,7,8}$.

The liver plays a key role in glutamine metabolism, using it to maintain acid-base homeostasis and to control levels of ammonia and urea in the bloodstream ${ }^{6}$. Glutamine is also an important substrate for enterocytes ${ }^{7,9}$. Studies suggest that the absorptive, proliferative, and barrier functions of the gut are influenced by glutamine ${ }^{9,10}$. Some authors regard glutamine as a limiting factor in immune system performance due to its widespread use by macrophages, neutrophils, and lymphocytes ${ }^{6,11}$. Furthermore, in stressful situations, demand for glutamine increases, far exceeding its supply ${ }^{10}$. Studies show that glutamine supplementation can prevent comorbidities in trauma patients and increase survival in animal models of infection. There is also experimental evidence from animal studies that glutamine supplementation may enhance colonic anastomosis healing and decrease bacterial translocation ${ }^{2,7,12,13}$.

Therefore, one might suppose that, in the presence of biliary tract obstruction, perioperative glutamine supplementation would minimize the harmful effects of jaundice and might aid colon healing. Within this context, the purpose of the present study was to evaluate the influence of glutamine and obstructive jaundice on left colon healing in rats.

\section{Methods}

The research project was approved by the institutional Animal Experimentation Ethics Committee (CEUA) (protocol UnBDoc 42873/2012).
The study sample comprised 16 healthy male Wistar rats (Rattus norvegicus). For ten days preoperatively, the animals were housed in cages at the UnB School of Medicine vivarium. Standard diet and water were provided ad libitum, and the animals were kept under a 12-hour light/dark cycle. All animals $(\mathrm{n}=16)$ underwent colotomy and bowel suture as described below and were randomly allocated across four groups differing as to common bile duct ligation vs. manipulation and glutamine supplementation vs. no supplementation (Table 1):

TABLE 1 - Group allocation.

\begin{tabular}{ccccc}
\hline & LG & L & M & MG \\
\hline Bowel suture & yes & yes & yes & yes \\
$*$ CDBL & yes & yes & no & no \\
$* *$ GS & yes & no & no & yes \\
\hline
\end{tabular}

*CDBL $=$ Common bile duct ligation

**GS=Glutamine supplementation

Animals in group LG underwent common bile duct ligation, followed by colotomy and bowel suture on postoperative day 7 . Glutamine ( $2 \%$ aqueous solution) was provided ad libitum from day 4 after ligation until the day of euthanasia.

Animals in group L underwent common bile duct ligation, followed by colotomy and bowel suture on postoperative day 7. No glutamine supplementation was provided.

Animals in group $\mathrm{M}$ underwent manipulation, but not ligation, of the common bile duct, followed by colotomy and bowel suture on postoperative day 7. No glutamine supplementation was provided.

Animals in group MG underwent manipulation, but not ligation, of the common bile duct, followed by colotomy and bowel suture on postoperative day 7 . Glutamine ( $2 \%$ aqueous solution) was provided ad libitum from day 4 after manipulation until the day of euthanasia.

\section{Operative technique}

\section{Common bile duct ligation}

In all animals, access to the common bile duct was achieved via a right subcostal incision $4 \mathrm{~cm}$ in length. In groups LG and L, the common bile duct was identified and ligated with 6-0 nylon thread (Figure 1). In groups MG e M, the common bile duct was merely manipulated. 


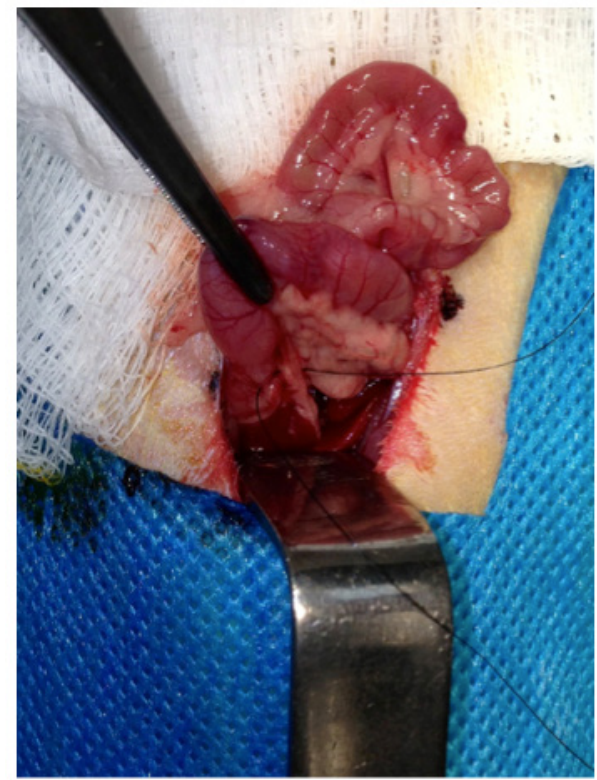

FIGURE 1 - Common bile duct ligation.

\section{Bowel suture}

Seven days after common bile duct ligation or manipulation, the animals underwent colotomy and bowel suture. First, the animals were weighed for calculation of anesthetic dosage. General anesthesia was then induced with xylazine hydrochloride $14 \mathrm{mg} / \mathrm{kg}$ and ketamine hydrochloride $114 \mathrm{mg} / \mathrm{kg}$ via intramuscular injection. Once anesthesia had been achieved, the animals were placed on the operating board in the supine position, with the forelimbs and hindlimbs fixed in abduction. The anterior abdominal wall was shaved and antisepsis performed with povidone-iodine.

The colon was accessed via a 4-cm midline laparotomy, with the incision starting $1 \mathrm{~cm}$ above the external genitalia and extending toward the sternum. In all animals, a longitudinal colotomy $2 \mathrm{~cm}$ in length was created on the left colon (Figure 2), followed by continuous longitudinal bowel suture with 6-0 nylon (Figure 3).

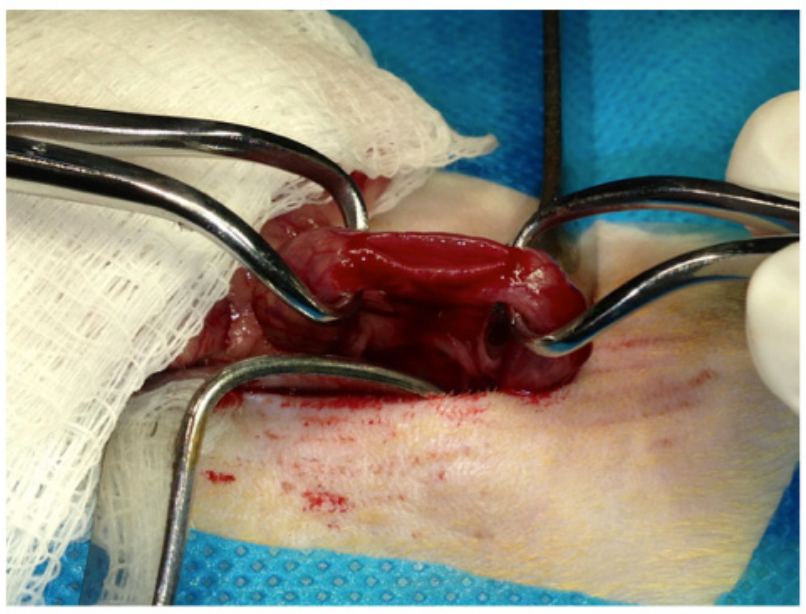

FIGURE 2 - Longitudinal colotomy.

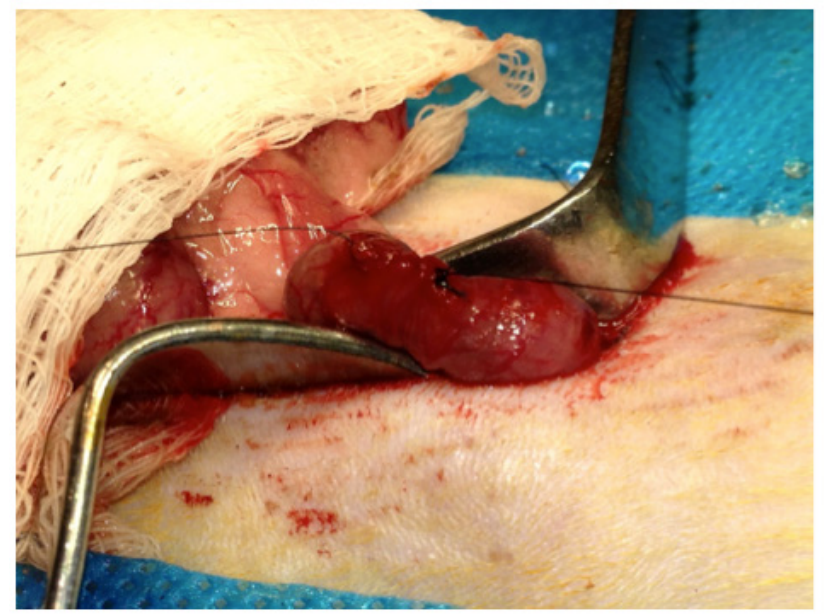

FIGURE 3 - Longitudinal bowel suture with continuous (running) stitches.

After both procedures, the abdominal wall was closed in two layers (myofascial and skin) of continuous sutures with 4-0 nylon. Postoperative analgesia consisted of tramadol, $28.5 \mathrm{mg} / \mathrm{kg}$ subcutaneously every $12 \mathrm{~h}$ for $48 \mathrm{~h}$, with the first dose administered $12 \mathrm{~h}$ after the procedure.

\section{Euthanasia}

On the day of euthanasia, the animals were again subjected to general anesthesia and antisepsis of the abdominal wall. The abdominal cavity was accessed via a midline laparotomy and the left colon was identified. The burst pressure of the colon segment containing the bowel suture was then measured with a Zurich brand Z.10.B manometer (Figure 4), as described by Durães et $a l .{ }^{14}$. This segment was then resected and a blood sample collected for determination of the bilirubin level. Finally, the animals were killed by anesthetic overdose.

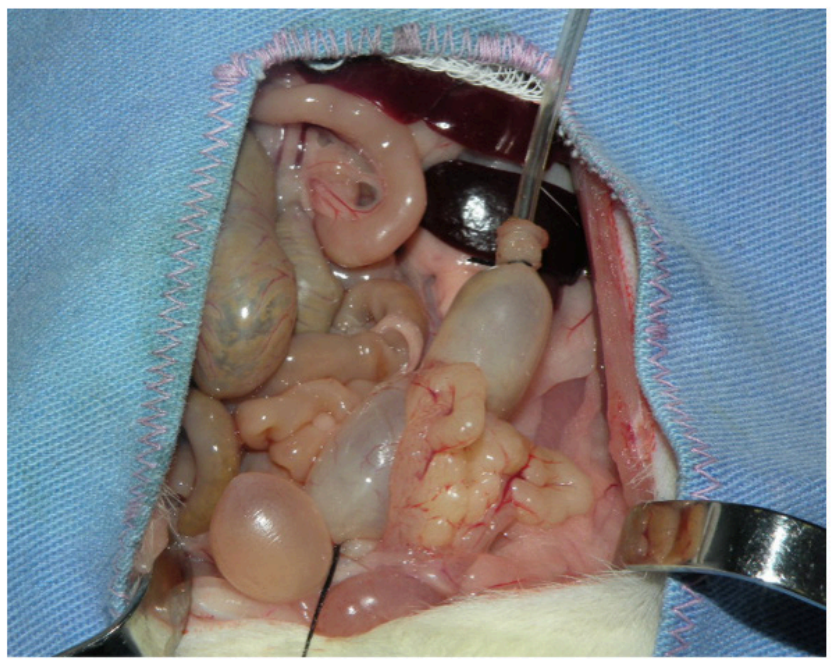

FIGURE 4 - Left colon inflated in the anatomical position with adhesions to determine the bowel suture bursting pressure. 


\section{Histological evaluation}

The resected colon specimens were examined under light microscopy by an experienced pathologist who was blinded to group allocation. All slides were stained with hematoxylin and eosin. The following parameters were evaluated: collagen, fibroblasts, mononuclear cells, polymorphonuclear cells, hemorrhage, congestion, neovascularization, edema, ulcers, necrosis, abscess, colonies, foreign body, and fibrin crust. The findings were noted as absent or present, and the intensity of the latter was graded on a qualitative scale as mild $(+)$, moderate $(+++)$, or marked $(+++)$.

\section{Statistical analysis}

All results are expressed as mean \pm standard error $(\mathrm{X} \pm$ SEM). Statistical analyses were carried out in blind fashion (i.e., without awareness of the procedures performed in each group), in the Statview software environment. The nonparametric MannWhitney $U$ test and repeated-measures analysis of variance (ANOVA) were used for pairwise comparisons of the variables of interest. The absolute and percent differences ( $\partial$ and $\partial \%$ respectively) between postoperative and preoperative body weight were also calculated. Spearman rank correlation coefficients were used to test for correlation between variables. $p$-values $\leq 0.05$ were deemed statistically significant.

\section{Results}

Body weight

Animals were weighed at the time of colon surgery (time point 1) and on the day of euthanasia (time point 2) (Figure 5).

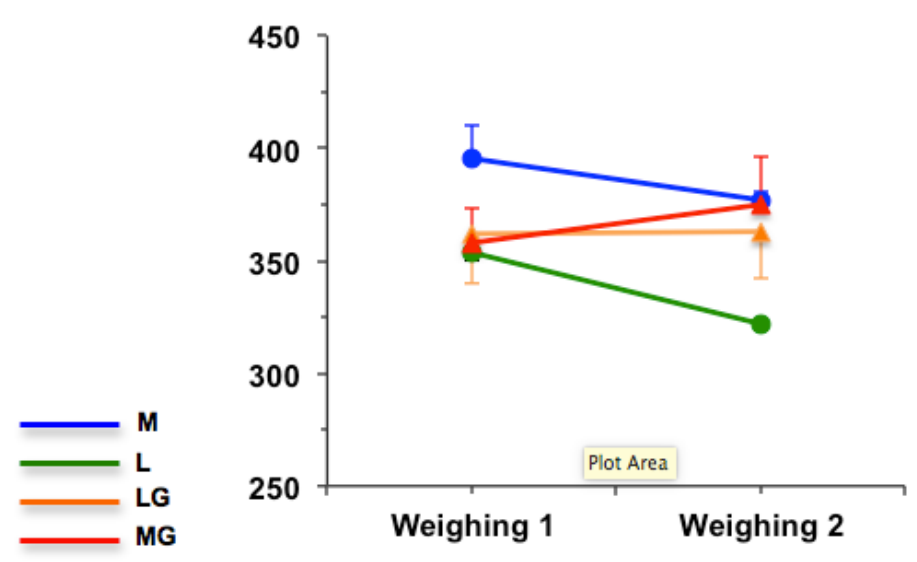

FIGURE 5 - Progression of body weight in the four study groups. MG vs. M p = 0.03; LG vs. L p = 0.002; MG vs. L $p=0.004 ;$ LG vs. M. $\mathrm{p}=0.08$ for the treatment $\mathrm{x}$ group interaction by repeated-measures ANOVA.
Rats in the glutamine supplementation groups (MG and LG) had a different pattern of weight change over the experiment as compared with non-supplemented animals (groups L and M). Animals receiving supplementation exhibited an increase in body weight, whereas those in the control group and those that underwent common bile duct ligation but did not receive supplementation lost weight during the experiment.

The difference in body weight (delta) in groups LG and $\mathrm{MG}$ was $1.25 \pm 1.0$ and $16.8 \pm 8.5 \mathrm{~g}$ respectively, vs. -18.2 $\pm 11.2 \mathrm{~g}$ in group $\mathrm{M}$ and $-31.5 \pm 7.0 \mathrm{~g}$ in group $\mathrm{L}(\mathrm{p}=0.02$ for all comparisons). Although the difference in body weight observed in group L was greater than that observed in group $\mathrm{M}$, the difference did not reach statistical significance. Conversely, weight gain in group MG was significantly greater than in group LG $(p=0.02)$. These delta values correspond to the following relative differences from baseline: $\mathrm{LG}=0.4 \pm 0.3 \% ; \mathrm{M}=-4.5$ $\pm 2.2 \% ; \mathrm{L}=-8.9 \pm 1.7 \%$; and $\mathrm{MG}=4.5 \pm 2.1 \%$. The results of these statistical comparisons were identical to those of statistical comparison of the delta values.

In short, animals who received glutamine supplementation had a positive weight balance as compared with animals that did not receive supplementation.

Comparison between groups MG and LG also revealed differences. The bile duct ligation group had a significantly less positive weight difference $(p=0.02)$. Therefore, common bile duct ligation had a negative effect on the weight balance of glutaminesupplemented animals.

\section{Total bilirubin (TB)}

Animals that underwent common bile duct ligation (groups L and LG) had significantly higher total bilirubin levels in blood. The mean TB level in group L was $1.16 \pm 0.44 \mathrm{mg} / \mathrm{dL}$, vs. $0.13 \pm 0.01 \mathrm{mg} / \mathrm{dL}$ in group $\mathrm{M}(\mathrm{p}=0.02)$ and $0.10 \pm 0.00 \mathrm{mg} / \mathrm{dL}$ in group $\mathrm{MG}(\mathrm{p}=0.03$ vs. $\mathrm{M})$. The mean TB level in group LG was $0.53 \pm 0.10 \mathrm{mg} / \mathrm{dL}$ ( $\mathrm{p}=0.02$ vs. $\mathrm{M}, \mathrm{p}=0.02$ vs. $\mathrm{MG}$ ).

\section{Direct bilirubin $(D B)$}

Animals that underwent common bile duct ligation (groups L and LG) had significantly higher direct bilirubin levels in blood. The mean DB level in group $\mathrm{L}$ was $0.73 \pm 0.31 \mathrm{mg} / \mathrm{dL}$, vs. $0.04 \pm 0.01 \mathrm{mg} / \mathrm{dL}$ in group $\mathrm{M}(\mathrm{p}=0.02)$ and $0.04 \pm 0.01 \mathrm{mg} / \mathrm{dL}$ in group $\mathrm{MG}(\mathrm{p}=0.02)$. The mean $\mathrm{DB}$ level in group LG was $0.33 \pm$ $0.07 \mathrm{mg} / \mathrm{dL}$ (Figure 6). 


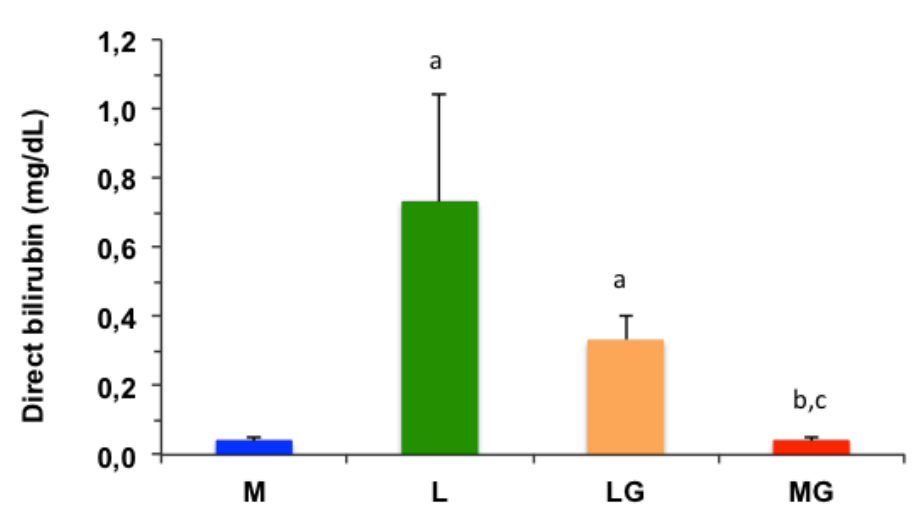

FIGURE 6 - Direct bilirubin levels (mg/dL) in the four study groups.

a: $p<0.05$ vs. CT; b: $p<0.05$ vs. L; c: $p<0.05$ vs. G.

\section{Indirect bilirubin (IB)}

Animals that underwent common bile duct ligation (groups L and LG) had significantly higher indirect bilirubin levels in blood: $0.43 \pm 0.14 \mathrm{mg} / \mathrm{dL}$ and $0.20 \pm 0.03 \mathrm{mg} / \mathrm{dL}$ vs. 0.09 $\pm 0.01 \mathrm{mg} / \mathrm{dL}$ in group $\mathrm{M}$ ( $\mathrm{p}=0.02$ for both comparisons). The IB level in group $\mathrm{MG}$ was $0.06 \pm 0.02 \mathrm{mg} / \mathrm{dL}(\mathrm{p}=0.02 \mathrm{vs}$. L).

The increase in DB levels in the common bile duct ligation groups was proportionally greater than the increase in IB, thus increasing the $\mathrm{DB} / \mathrm{TB}$ ratio: $\mathrm{L}=0.61 \pm 0.03 ; \mathrm{LG}=0.61 \pm$ $0.03 ; \mathrm{M}=0.31 \pm 0.05 ; \mathrm{MG}=0.39 \pm 0.11$.

\section{Bursting pressure}

There were no statistically significant differences in bursting pressure across the four study groups and the values are presented in mean \pm SEM for the four group: LG vs. group $M$ $(110 \pm 28$ vs. $173 \pm 12 ; \mathrm{p}=0.08)$. Groups $\mathrm{L}$ and $\mathrm{MG}$ were not different from group $\mathrm{M}(156 \pm 12$ and $118 \pm 22)$. Burst pressure levels were negatively associated with $\mathrm{DB} / \mathrm{TB}$ ratios (Figure 7).

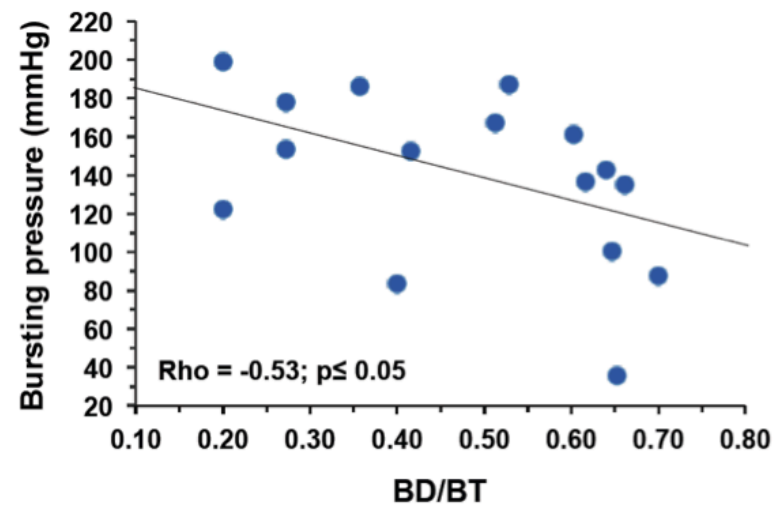

FIGURE 7 - Correlation between DB/TB ratio and bursting pressures in the four study groups (pooled analysis).

\section{Histopathological examination}

Some histopathology findings are illustrated in Figure 8 and all findings in the four groups are summarized in Table 2.

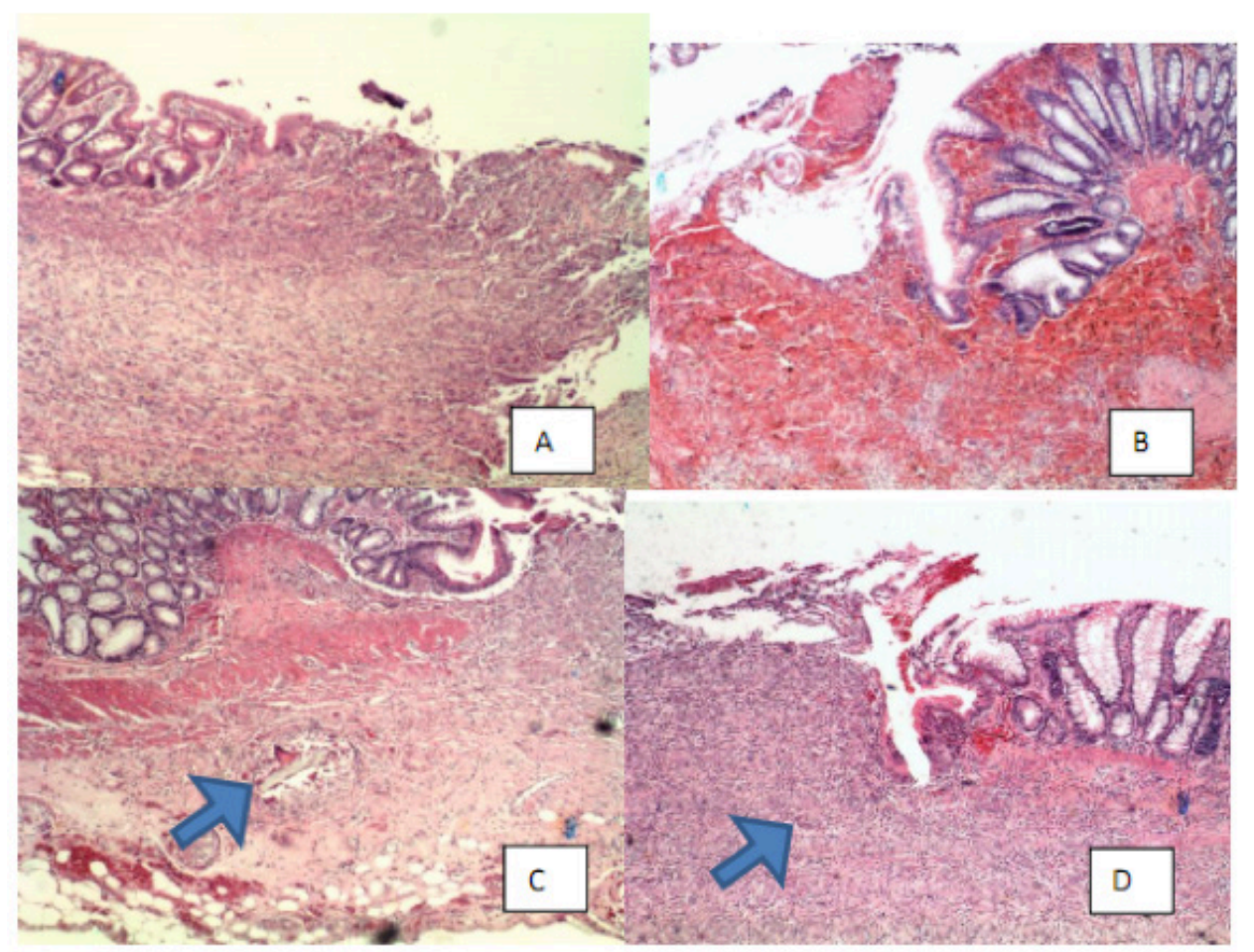

FIGURE 8 - Photomicrograph of ulcerated mucosa in the area of the scar in A, with hemorrhage in $\mathbf{B}$, granuloma with foreign body (arrow) in $\mathbf{C}$ and fibrin crust and fibrosis (arrow) in D. HE x100. 
TABLE 2 - Results of histopathological analysis, stratified by the four groups LG, L, M and MG.

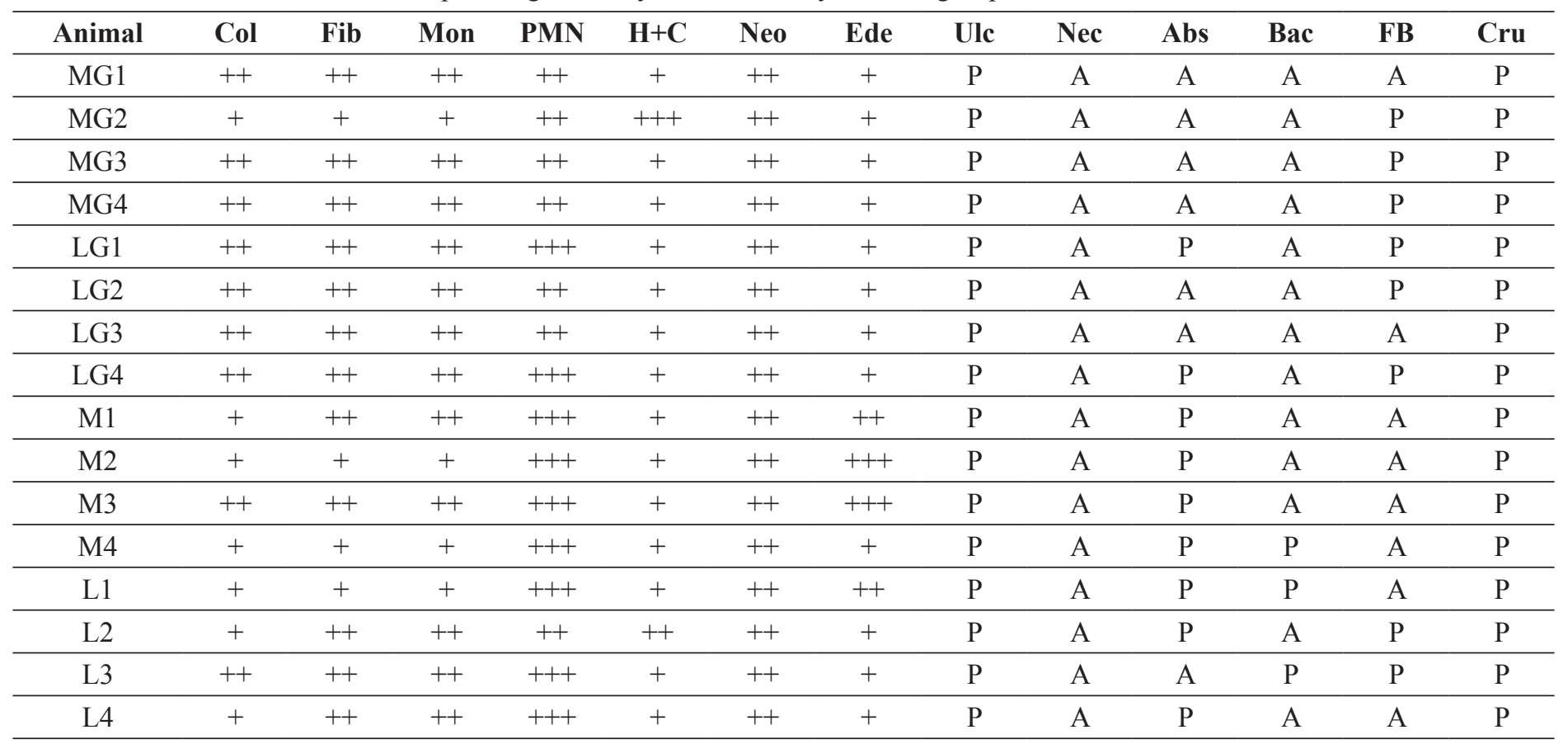

Col: collagen; Fib: fibroblasts; Mon: mononuclear cells; PMN: polymorphonuclear cells;

$\mathrm{H}+\mathrm{C}$ : hemorrhage and congestion; Neo: neovascularization; Ede: edema; Ulc: ulceration; Nec: necrosis; Abs: abscess; Bac: bacterial colonies; FB: foreign body; Cru: crust; P: present; A: absent.

Animals in the glutamine-supplemented groups exhibited less edema, polymorphonuclear lymphocytes, bacterial colonies, and abscess formation than rats in the non-supplemented groups. Glutamine supplementation was associated with increased collagen formation.

\section{Discussion}

The results obtained in this experiment strengthen the evidence base for the experimental model of obstructive jaundice used herein. Animals that underwent common bile duct ligation exhibited significantly higher bilirubin levels. Furthermore, based on the reference ranges reported in the literature, the animals in the duct ligation groups may be considered icteric, as the mean TB concentrations in these animals were above the reference ranges for rats reported in other studies ${ }^{15}$.

Body weight analyses showing a positive effect of glutamine supplementation may be explained by the additional amino acid intake of the supplemented animals rather than by any specific advantage conferred by glutamine itself. The lack of administration of an isonitrogenous control supplement to animals in the non-glutamine groups is a possible source of bias for this study.

Animals in group MG gained more weight than those in group LG, which suggests a negative metabolic effect of common bile duct ligation. This may be explained by the hepatic injury induced by biliary obstruction and by the lack of biliary enzymes in the digestive tract of animals after common bile duct ligation, leading to malabsorption.

The reduction in edema, polymorphonuclear cells, bacterial colony counts, and abscess formation among rats in the glutamine-supplemented groups may be understood to represent a protective effect of this amino acid against bacterial invasion of host tissues. This finding is consistent with the existing literature, which has demonstrated a protective role of glutamine against bacterial translocation ${ }^{16,17}$. Additional studies are required to investigate the clinical applicability of this finding in humans and thus create new perspectives for therapy. Another interesting finding concerns the increased collagen formation in the supplemented groups, which was not, however, associated with any increase in colon strength. Indeed, from a tensile strength standpoint, glutamine supplementation had no effect whatsoever on healing.

The absence of a significant negative effect of jaundice on colon strength runs counter to the existing literature, and may be at least partly attributable to the small sample size of the present study. Statistical comparison between groups L and LG showed a trend toward negative effect $(\mathrm{p}=0.08)$, as did the inverse correlation between burst pressure and serum DB/TB ratio. At any rate, this potential negative effect does not seem to be countered by glutamine supplementation, as there were no differences between the supplemented groups and their respective control groups. 


\section{Conclusion}

Glutamine supplementation reduced bacterial colonization and abscess formation and increased collagen formation, but had no effect on the bursting pressure of colonic scars in animals with or without experimentally induced biliary obstruction.

\section{References}

1. Arantes VN, Ozawa RY, Fagundes-Pereira WJ, Barbosa AJA, Petroianu A. Influência da icterícia obstrutiva na cicatrização da pele e de anastomose jejunal em ratos. Rev Col Bras Cir. 1999 SeptOct;26(5):269-73. doi: 10.1590/S0100-69911999000500003.

2. Hall JC, Heel K, McCauley R. Glutamine. Br J Surg.1996 Mar;83:305-12. doi: 10.1002/bjs.1800830306.

3. Arnaud JP, Humbert W, Eloy MR, Adolfo M. Effect of obstructive jaundice on wound healing: an experimental study in rats. Am J Surg. 1981 May;141(5):593-6. doi: 10.1016/0002-9610(81)90059-3.

4. Paiva Neto MC, Almeida REF, Xavier MM, Takano GHS, Silva Jr OC, da Cruz CAT, Sousa JB. Influence of glutamine on morphological and functional changes of liver in the presence of extrahepatic biliary obstruction in rats. Acta Cir Bras. 2010 JulAug;25(4):375-80. doi: 10.1590/S0102-86502010000400014.

5. Lopes-Paulo F. Efeitos da glutamina sobre a parede intestinal e sua aplicabilidade potencial em coloproctologia. Rev Bras Coloproctol. 2005 Jan-Mar;25(1):75-8.

6. Haussinger D, Schliess F. Glutamine metabolism and signaling in the liver. Front Biosci. 2007 Jan;12:371-91. doi: 10.2741/2070.

7. Tekin E, Taneri F, Ersoy E, Oguz M, Eser E, Tekin I, Bozkurt S, Onuk E. The effects of glutamine-enriched feeding on inciosional healing in rats. Eur J Plast Surg. 2000 Feb;23(2):78-81. doi: 10.1007/ s002380050019.

8. Shen-Chen SM, Hung KS, Ho HT, Chen WJ, Eng HL. Effect of glutamine and bile acid on hepatocyte apoptosis after bile duct ligation in the rat. World J Surg. 2004 May;28(5):457-60. doi: 10.1007/s00268-004-7189-7.

9. Salvalaggio PRO, Neto CZ, Tolazzi ARD, Gasparetto EL, Coelho JCU, Campos ACL. Oral glutamine does not prevent bacterial translocation in rats subjected to intestinal obstruction and Escherichia coli challenge but reduces systemic bacteria spread. Nutrition. 2002 Apr;18(4):334-7. doi: http://dx.doi.org/10.1016/ S0899-9007(01)00750-X.

10. Margaritis VG, Filos KS, Michalaki MA, Scopa CD, Spiliopoulou I, Nikolopoulou VN, Vagianos CE. Effect of oral glutamine administration on bacterial translocation, endotoxemia, liver and ileal morphology, and apoptosis in rats with obstructive jaundice. World J Surg. 2005 Oct;29(10):1329-34. doi: 10.1007/s00268-005-7721-4.

11. Newsholme P. Why is L-glutamine metabolism important to cells of the immune system in health, postinjury, surgery or infection? J Nutr. 2001 Sep;131(9 Suppl):2515S-22S. PMID: 11533304.
12. El-Malt M, Ceelen W, Boterberg T, Claeys G, de Hemptinne B, de Neve W, Pattyn P. Does the addition of glutamine to total parenteral nutrition have benefical effect on the healing of colon anastomosis and bacterial translocation after preoperative radiotherapy? Am J Clin Oncol. 2003 Jun;26(3):e54-9. PMID: 12796616.

13. Guven A, Pehlivan M, Gokpinar I, Gurleyik E, Çam M. Early glutamineenriched enteral feeding facilitates colonic anastomosis healing: light microscopic and immunohistochemical evaluation. Acta Histochem. 2007 Mar;109(2):122-9. doi: 10.1016/j.acthis.2006.11.004.

14. Duarães LC, Durães EF, Lobato LF, Oliveira PG, Sousa JB. Correlation between bursting pressure and breaking strength in colonic anastomosis. Acta Cir. Bras. 2013 Jun;28(6):447-52. doi: 10.1590/S0102-86502013000600008.

15. Melo MGD, Dória GAA, Serafini MR, Araújo AAS. Reference values of hematological and biochemical rats (Rattus norvegicus Wistar strain) from the central animal house of the Federal University of Sergipe. Scientia Plena. 2012 Oct;8(4):1-6.

16. Karatepe O, Acet E, Battal M, Adas G, Kemik A, Altiok M, Kamali G, Koculu S, Catay A, Kamali S, Karahan S. Effects of glutamine and curcumin on bacterial translocation in jaundiced rats. World $\mathrm{J}$ Gastroenterol. 2010 Sep;16(34):4313-20. PMID: 20818815.

17. Sözen S, Topuz O, Uzun AS, Cetinkünar S, Das K. Prevention of bacterial translocation using glutamine and melatonin in small bowel ischemia and reperfusion in rats. Ann Ital Chir. 2012 MarApr;83(2):143-8. PMID: 22462335.

\section{Correspondence:}

João Batista de Sousa

Campus Universitário Darcy Ribeiro-UnB

Faculdade de Medicina

Laboratório de Cirurgia Experimental

70910-900 Brasília - DF Brasil

Tel.: (55 61)9984-2845

sousajb@unb.br

Received: Sep 29, 2014

Review: Nov 28, 2014

Accepted: Dec 30, 2014

Conflict of interest: none

Financial source: $\mathrm{CNPq}$

${ }^{1}$ Research performed at Laboratory of Experimental Surgery, School of Medicine, Brasília University (UnB), Brazil. 